\title{
Development of a monoclonal antibody specific to the endonuclease domain of the human LINE-1 ORF2 protein
}

\author{
Mark Sokolowski ${ }^{1 \dagger}$, Cecily B DeFreece ${ }^{2 \dagger}$, Geraldine Servant ${ }^{3}$, Kristine J Kines ${ }^{1}$, Dawn L deHaro ${ }^{1}$ \\ and Victoria P Belancio ${ }^{1 *}$
}

\begin{abstract}
Background: LINE-1 (L1) retrotransposons are common occupants of mammalian genomes representing about a fifth of the genetic content. Ongoing L1 retrotransposition in the germ line and somatic tissues has contributed to structural genomic variations and disease-causing mutations in the human genome. L1 mobilization relies on the function of two, self-encoded proteins, ORF1 and ORF2. The ORF2 protein contains two characterized domains: endonuclease and reverse transcriptase.

Results: Using a bacterially purified endonuclease domain of the human L1 ORF2 protein, we have generated a monoclonal antibody specific to the human ORF2 protein. We determined that the epitope recognized by this monoclonal antibody includes amino acid 205, which is required for the function of the L1 ORF2 protein endonuclease. Using an in vitro L1 cleavage assay, we demonstrate that the monoclonal anti-ORF2 protein antibody partially inhibits L1 endonuclease activity without having any effect on the in vitro activity of the human AP endonuclease.

Conclusions: Overall, our data demonstrate that this anti-ORF2 protein monoclonal antibody is a useful tool for human L1-related studies and that it provides a rationale for the development of antibody-based inhibitors of L1-induced damage.
\end{abstract}

Keywords: Endonuclease, In vitro assay, L1, L1 antibody, LINE-1, ORF2, Retrotransposition

\section{Background}

Long interspersed element-1 (L1) is an autonomous non-long terminal repeat retrotransposon that has parasitized the human genome for millions of years. L1 has shaped the evolution of the human genome through a copy-and-paste mobilization of itself [1], as well as the short interspersed element (SINE) Alu [2], SINE-VNTRAlu elements (SVA) [3], and processed cellular transcripts [4]. Functional full-length L1 transcripts contain two open reading frames (ORFs) encoding ORF1 and ORF2 proteins (ORF1p and ORF2p, respectively) (Figure 1A). These L1 proteins exhibit cis-preference for their encoding L1 mRNA [5-7] and are utilized in trans by the Alu and

\footnotetext{
* Correspondence: vperepe@tulane.edu

${ }^{\dagger}$ Equal contributors

'Department of Structural and Cellular Biology, Tulane School of Medicine, Tulane Cancer Center, and Tulane Center for Aging, New Orleans, LA 70112, USA

Full list of author information is available at the end of the article
}

SVA elements $[2,3,8]$. L1, Alu, and SVA form ribonucleoprotein (RNP) particles which reach the nucleus to complete their replication cycles by integrating in the host genome via a process of target-primed reverse transcription $[9,10]$. This copy-and-paste process has produced approximately 500,000 L1 loci, accounting for about $17 \%$ of the human genome, and over $1,000,000$ copies of Alu, which comprise about $11 \%$ of our genome [11]. The majority of the L1 loci are $5^{\prime}$ truncated with about 80 to 100 full-length L1 copies demonstrated to be retrotranspositionally active [12-16].

L1 proteins are produced from the full-length L1 mRNA with significantly different efficiencies, mostly owing to the unconventional translation from the bicistronic L1 mRNA [17-20] (Figure 1A). Detection of both L1-encoded proteins is important in understanding L1 biology since they play critical, but different roles in the L1 replication cycle. The human ORF2p is a 149 kilodalton $(\mathrm{kDa})$ protein 


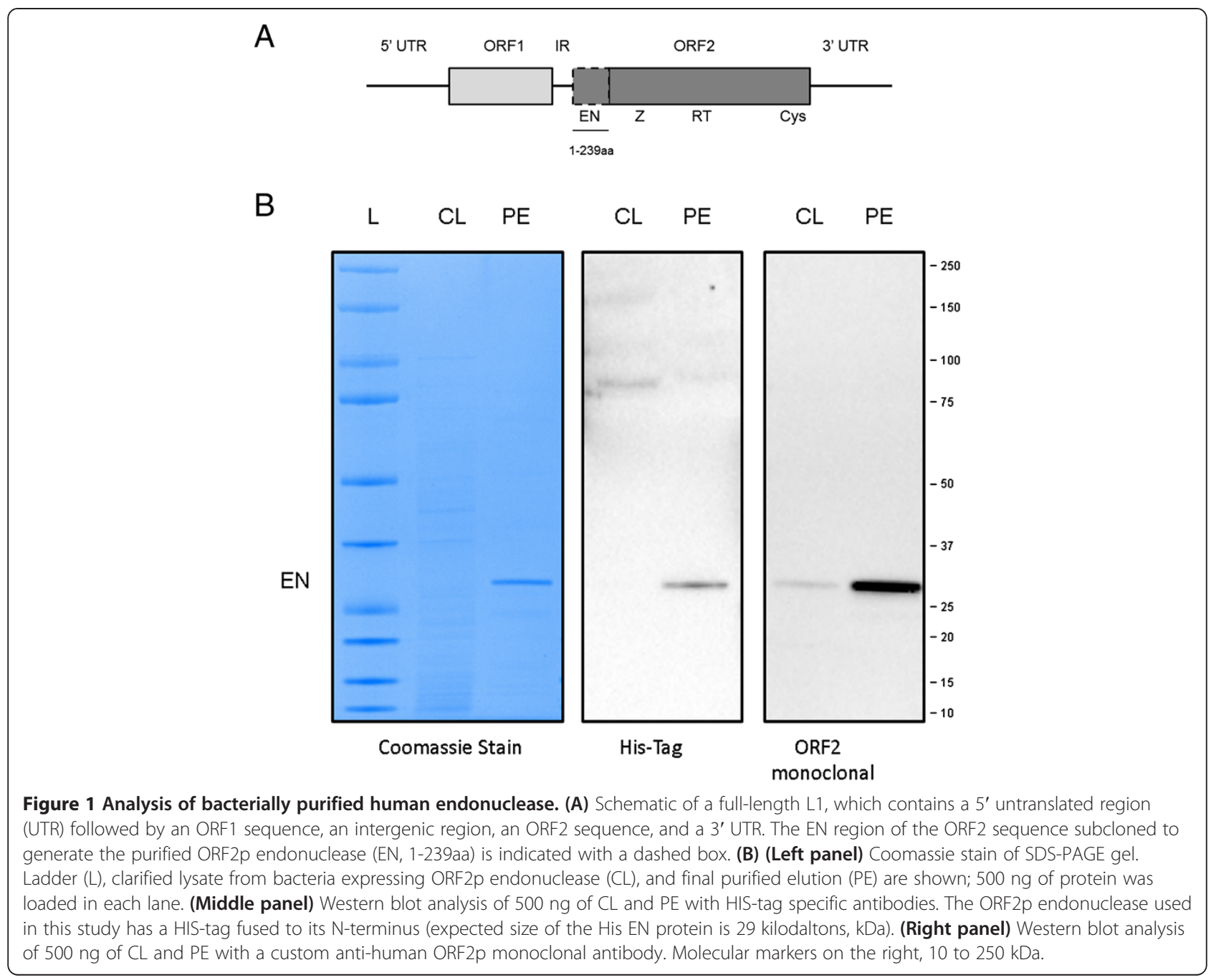

with three annotated domains: an N-terminal endonuclease (EN) domain [21], a reverse transcriptase (RT) domain [22], and a C-terminal domain [23] with putative RNA binding activity [24]. Human and mouse L1 ORF2 proteins exhibit a high degree of sequence homology and conservation of function making findings in mouse model systems biologically relevant to the replication cycle of the human L1 $[25,26]$. Although much has been learned about ORF2p function in vitro and in mammalian cells using overexpressed tagged ORF2 proteins and polyclonal antiORF2p antibodies [27-30], having a monoclonal antibody that can detect the untagged human ORF2 protein would be a useful molecular tool to study the requirements for the human L1 ORF2p expression and activity. It would also aid in advancing our appreciation of the ORF2p impact on host genome stability and in understanding the consequences of its activity to human health.

To satisfy the need for a continuous source of antibodies to detect L1 ORF2p, we developed an anti-ORF2p monoclonal antibody capable of recognizing sequences within the endonuclease domain of the human ORF2 protein. This monoclonal antibody is specific to the human ORF2p and can detect the full-length ORF2 protein, as well as truncated ORF2 proteins overexpressed in mammalian cells. Using a recombinant human L1 endonuclease purified from bacterial cells as a standard [31,32], we determined the sensitivity of this monoclonal anti-human ORF2p antibody. The unique location of the epitope, encompassing a position required for the function of the human endonuclease domain, allowed us to test the ability of this monoclonal anti-ORF2p antibody to inhibit L1 endonuclease activity in vitro using a fluorescence-based cleavage assay.

\section{Results}

\section{Generation of monoclonal antibody against human L1} ORF2 $p$ endonuclease

A recombinant human protein containing an ORF2p EN domain $\mathrm{N}$-terminally fused to a His-tag was purified from bacterial cells as previously described [31-33], subjected 
to SDS-PAGE, and visualized using Coomassie stain (Figure 1B, Coomassie panel, expected product of 29 $\mathrm{kDa})$. The efficiency of purification was also confirmed using antibodies against the His-tag fused to the Nterminus of the ORF2p EN (Figure 1B, His-Tag panel). This purified recombinant human EN protein was used for the immunization of Balb/c mice to generate monoclonal anti-ORF2p antibodies following a standard immunization protocol (see Methods). This approach resulted in a positive hybridoma clone which was used to produce the purified anti-ORF2p monoclonal antibodies. Western blot analysis using this custom ORF2p monoclonal antibody detected a product of the expected size in the clarified lysate and the final elution of the human EN protein used for inoculation (Figure 1B, ORF2 monoclonal panel).

\section{Anti-ORF2p monoclonal antibody is specific to the ORF2 protein of human origin}

We determined that our anti-ORF2p monoclonal antibody detects full-length ORF2p and ORF2p endonuclease in total cell lysates from 293 cells transiently transfected with plasmids containing human codon-optimized full-length ORF2 or the ORF2 endonuclease sequences (Figure 2A, lane hORF2 and hEN). Because the endonuclease domain of the L1 ORF2 protein is highly conserved between the human and mouse ORF2 proteins, we tested whether our antibody discriminates between ORF2 proteins of human and mouse origin. Plasmids encoding mouse codon-optimized full-length ORF2 or ORF2 endonuclease sequences were transiently transfected into 293 cells and total cellular lysates were analyzed by SDS-PAGE followed by immunoblotting with the anti-ORF2p monoclonal antibody. This approach determined that the anti-ORF2p monoclonal antibody does not detect mouse ORF2 or EN proteins (mORF2p and mENp, respectively) even though it detected both human ENp and ORF2p (Figure 2A, monoclonal Ab panel). The mouse ENp and ORF2p were detected when Western blot analysis was performed with polyclonal antibodies raised against the endonuclease domain of the mouse ORF2p [28] (Figure 2B, mouse Ab panel) confirming that the proteins are expressed under these transfection conditions.

\section{Anti-ORF2p monoclonal antibody recognizes an epitope which includes amino acid 205 of the human ORF2p endonuclease}

Many experimental approaches designed to analyze the expression and function of ORF2p involve the use of both functional and non-functional ORF2 proteins. The most commonly used mutations, which abolish the activity of the ORF2p endonuclease, are D205A and H230A $[21,34]$. Western blot analysis of total cellular lysates from human and mouse cells transiently transfected with EN or EN 205, 230 plasmids containing codon-optimized sequences producing functional or non-functional (D205A, H230A double mutant) human endonucleases demonstrated that the anti-ORF2p monoclonal antibody detects the active, but not the mutated, endonuclease protein (Figure 3A, monoclonal; Additional file 1: Figure S1, monoclonal). Both proteins were detected using the polyclonal anti-ORF2p antibody [28] (Figure 3A; Additional file 1: Figure S1).

To determine which EN mutation is responsible for the loss of detection by our anti-ORF2p monoclonal antibody, total cellular lysates from cells transiently transfected with EN 205 and EN 230 plasmids expressing non-functional endonucleases with D205A or H230A mutations were used for Western blot analysis with the anti-ORF2p monoclonal antibody (Figure 3B, monoclonal). This approach demonstrated that the anti-ORF2p monoclonal antibody detects ENp containing the H230A mutation, but not the ENp with the D205A mutation (Figure 3B, monoclonal). Both ENp mutants are readily detected with the antiORF2p polyclonal antibody $[27,28]$, demonstrating that both proteins are produced under these transfection conditions (Figure 3B, polyclonal). A similar result was obtained when the monoclonal anti-ORF2p antibody was used to detect transiently expressed functional (ORF2) and non-functional (single and double mutants) fulllength human ORF2 proteins (ORF2 205, ORF2 230, and ORF2 205,230, respectively) as well as truncated, functional, and double mutant human ORF2 proteins (ENz and ENRT) [28] (Figure 4A-E, ORF2, ENz, and ENRT). The anti-ORF2p monoclonal antibody specifically detected functional, but not the non-functional ENz, ENRT, and ORF2 proteins containing the D205A and $\mathrm{H} 230 \mathrm{~A}$ mutations, even though all of these proteins were produced in these cells as confirmed by Western blot analysis using polyclonal anti-ORF2p antibodies (Figure 4D,E). These results support that the epitope recognized by the anti-ORF $2 p$ monoclonal antibody includes amino acid 205 of the human ORF2p endonuclease domain.

\section{Sensitivity of the anti-ORF2 $p$ monoclonal antibody}

The advent of L1 expression plasmids containing codonoptimized sequences greatly facilitated our ability to detect L1-encoded proteins in transfected mammalian cells $[35,36]$. However, it remains important to study L1 proteins generated from wild-type L1 sequences and to understand the difference in expression levels between proteins generated from codon-optimized and wild-type L1 sequences. As with the wild-type full-length L1 and ORF2 expression plasmids, codon-optimized full-length L1 expression plasmids produce much less ORF2 protein than those containing a codon-optimized ORF2 sequence 


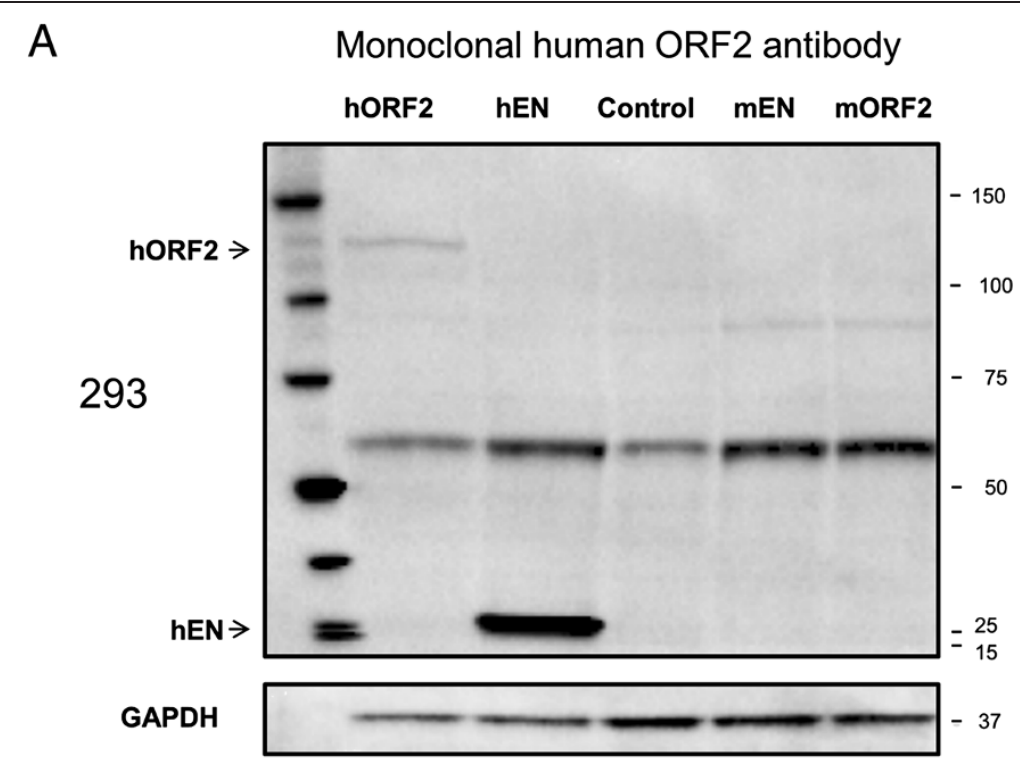

B

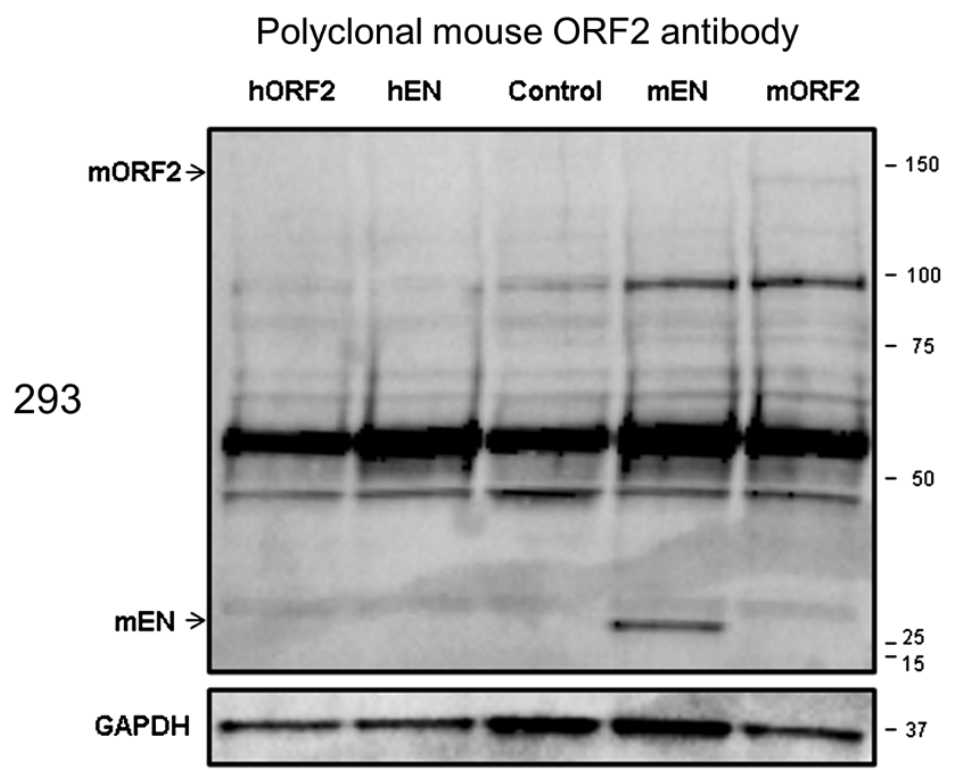

Figure 2 Analysis of specificity of the custom anti-human ORF2p monoclonal antibody in human cells. (A) Western blot analysis of mouse and human ORF2 (predicted size 150 and $149 \mathrm{kDa}$, respectively) and EN (predicted size 30 and $26 \mathrm{kDa}$, respectively) proteins generated from expression plasmids containing codon-optimized human ORF2 (hORF2), a codon-optimized sequence corresponding to the human ORF2 endonuclease fragment (hEN), codon-optimized mouse ORF2 (mORF2), and a codon-optimized sequence corresponding to the mouse ORF2 endonuclease fragment (mEN) transiently transfected in 293 cells. Custom anti-human ORF2p monoclonal antibody specifically detects proteins of human origin. (B) Western blot analysis of the same samples as in A was performed with custom anti-mouse ORF2p polyclonal antibodies which specifically detect proteins of mouse origin. Control lane indicates cells transiently transfected with an empty vector. GAPDH is used as a loading control; 15 to $150 \mathrm{kDa}$ on the right indicate positions of molecular markers.

$[20,25]$. Consistent with this fact, our anti-ORF2p monoclonal antibody detected different levels of ORF2p in cells transfected under the same conditions with L1 expression plasmids containing wild-type or codon-optimized sequences [6,36] (Figure 5). Transient transfection of 293 cells with plasmids containing codon-optimized ORF2 or full-length wild-type L1 sequences produced the highest and the lowest levels of ORF2 protein, respectively. Transfection of increasing amounts of plasmids containing codon-optimized or wild type full-length L1 sequences demonstrated that detectable levels of ORF2p were observed when 2 and $4 \mu \mathrm{g}$ of the respective plasmids were used. No signal consistent with detection of endogenous ORF2p in 293, Ntera2, nor HeLa cells was observed 


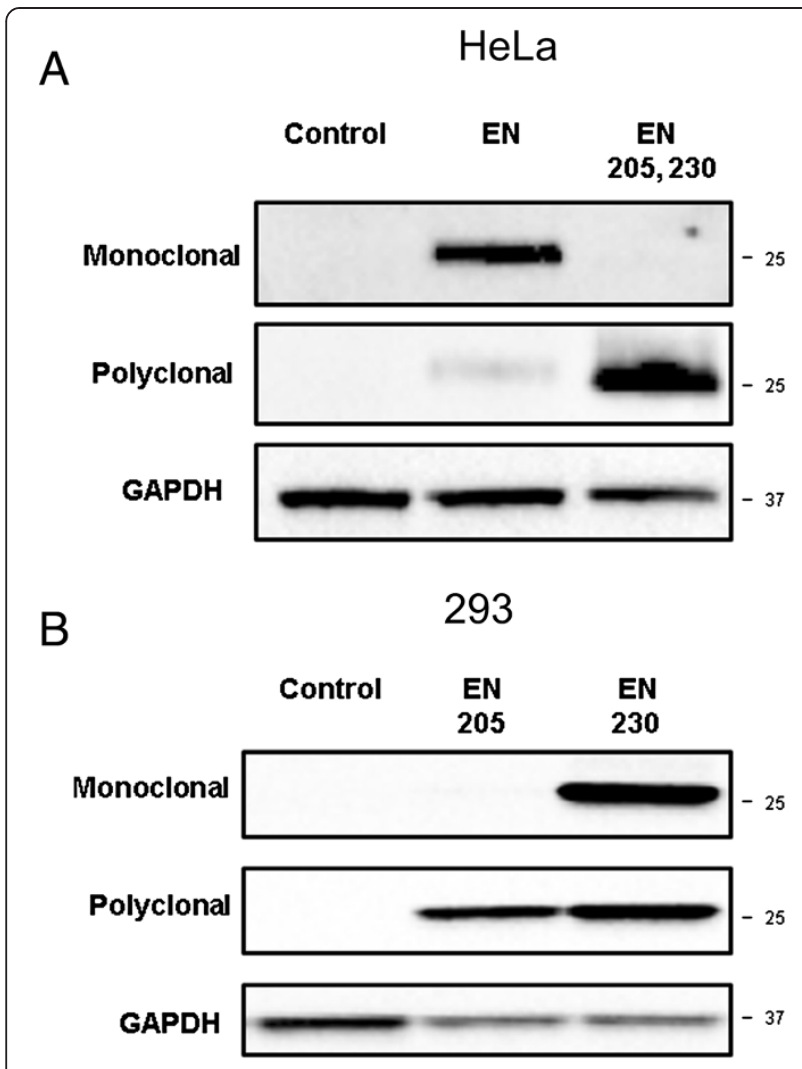

Figure 3 Analysis of expression of functional and nonfunctional human ORF2 protein in human cells. (A) Western blot analysis of proteins generated from expression plasmids containing codon-optimized, functional ORF2 endonuclease sequence (EN) and non-functional ORF2 endonuclease sequence transiently transfected in HeLa cells. Western blot analysis is performed with anti-human ORF2p monoclonal antibody (top), the previously described antihuman ORF2p endonuclease polyclonal antibodies (middle), and GAPDH antibodies (bottom). The non-functional ORF2 endonuclease sequence $(E N 205,230)$ has mutations resulting in expression of inactive ENp with D205A and H230A mutations. (B) The same experiment and analysis as in A, but using 293 cells. Western blot analysis of codon-optimized, non-functional ORF2 endonuclease sequences containing single inactivating mutations D205A or H230A (EN205 and EN 230, respectively) transiently transfected in 293 cells with anti-human ORF2 monoclonal antibody (top) or previously described anti-human ORF2p endonuclease polyclonal antibodies (middle). Expected EN protein size is $26 \mathrm{kDa}$. Control lane indicates cells transiently transfected with an empty vector; 25 and $37 \mathrm{kDa}$ on the right indicate positions of molecular markers.

(Additional file 2: Figure S2). Using the recombinant human endonuclease purified from bacterial cells as a standard, we determined that $27.6 \mu \mathrm{g}$ of our anti-ORF2p monoclonal antibody is able to detect $10 \mathrm{ng}\left(2.2 \times 10^{17}\right.$ molecules) of the purified hEN under these blotting conditions (Figure 6A). Based on the standard curve generated by Western blot analysis of the recombinant human EN purified from bacterial cells, we determined that transfection of expression plasmids containing codon-optimized human L1 sequences produce 5 to 6 times more endonuclease protein than that observed from cells transfected with equivalent amounts of plasmids containing wild-type sequences (Figure 6, ENwt and ENco).

Monoclonal anti-ORF2p antibody inhibits L1 endonuclease activity in an in vitro endonuclease cleavage assay

The unique epitope location within the L1 EN as well as the antibody's ability to detect natively folded ORF2p endonuclease purified from bacterial cells (Additional file 3: Figure S3) open a possibility that the monoclonal antibody may inhibit L1 endonuclease activity. For this purpose, a previously reported in vitro endonuclease cleavage assay was used to measure L1 EN activity [31,32]. Figure 7A shows a schematic of the DNA products expected to be observed upon cleavage of the substrate DNA by the L1 EN at the L1 EN site present in the template DNA sequence. Figure 7B demonstrates detection of the expected cleavage products resolved by PAGE when a bacterially purified, functional human L1 EN protein is present in the reaction. The addition of increasing amounts of the monoclonal anti-ORF2p antibody resulted in about $25 \%$ reduction of the cleaved products (Figure 7B). This effect was not observed when an unrelated, anti-ORF1p antibody was included in the reaction (Figure 7C). A similar in vitro endonuclease cleavage assay using a functionally-related recombinant human apurinic/ apyrimidinic endonuclease 1 (APE 1), which shares sequence homology with the L1-encoded endonuclease, was used to test the specificity of this effect. We observed no change in the APE 1 activity upon the addition of the highest amount of the L1 EN-specific antibody (200 nM; Additional file 4: Figure S4).

\section{Discussion}

L1 is responsible for all of the retrotransposon-induced genomic instability in the human genome, as it is the only active source of the functional ORF1 and ORF2 proteins required for mobilization of LINEs, SINEs, and SVA elements [37-42]. L1 expression and retrotransposition are suppressed by many diverse cellular pathways in order to minimize the genomic damage inflicted by L1 activity [20,43-50]. L1 encodes an ORF2 protein with several identified functions essential for the retrotransposition process. These include the endonuclease [21] and reverse transcriptase [22] activities, and a putative RNA binding domain within the C-terminus of the protein [24]. Studies geared toward understanding the biological relevance of this multifunctional protein and its effect on human health necessitate manipulations involving changes in protein sequence as well as characterization of the expression of resulting ORF2p variants in vitro, in cultured cells, and in vivo. To satisfy this requirement, polyclonal antibodies against the 


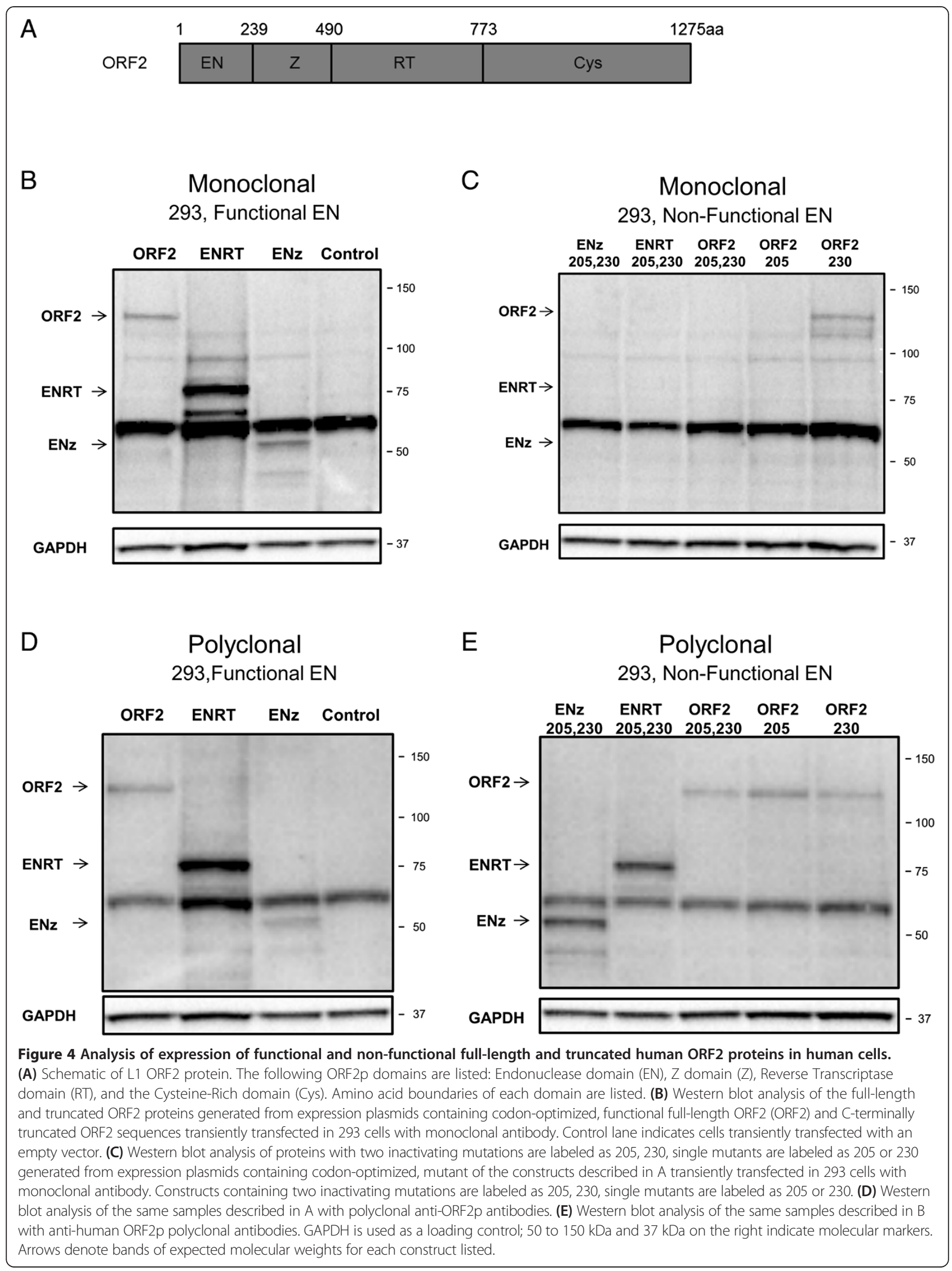




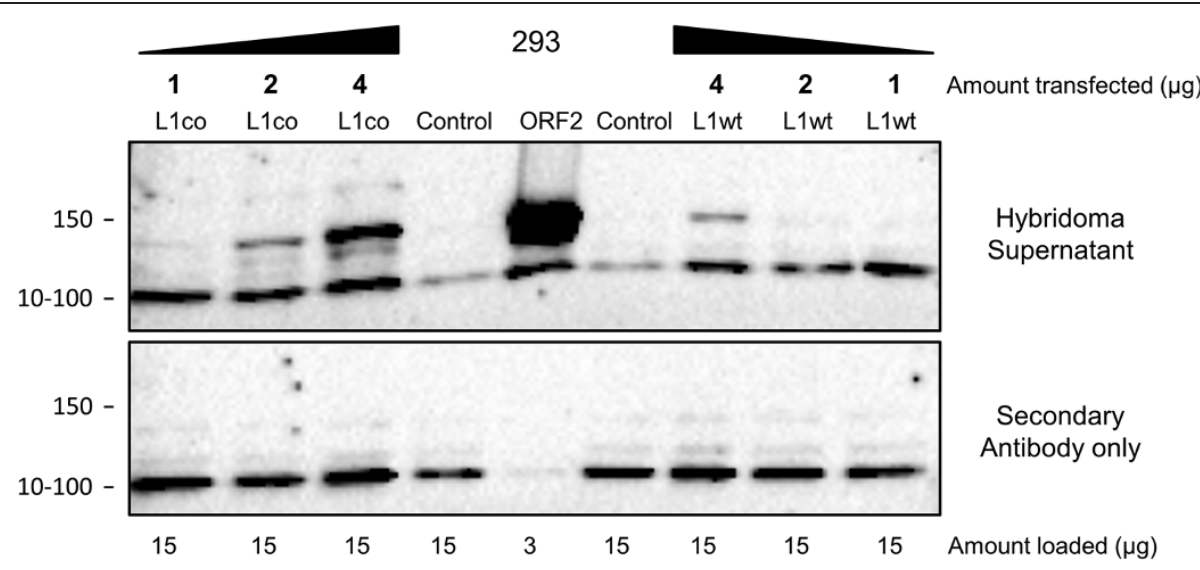

Figure 5 Analysis of ORF2p generated from a functional wild-type and a functional codon-optimized full-length L1 expression plasmids in $\mathbf{2 9 3}$ cells. (Top) Western blot analysis of ORF2p generated from expression plasmids containing a full-length wild-type L1 (L1wt), a full-length codon-optimized L1 (L1CO), or a codon-optimized ORF2 transiently transfected in 293 cells with supernatant collected from cultured hybridoma cells producing anti-ORF2 antibody; 293 cells were transfected with 1, 2, or $4 \mu \mathrm{g}$ of the L1wt or L1co expression plasmids or $2 \mu \mathrm{g}$ of the ORF2 expression plasmid and total protein was harvested 24 hours after transfection. Control lane indicates cells transiently transfected with an empty vector. Positions of molecular markers are indicated on the right as 100 or $150 \mathrm{kDa}$. (Bottom) The same experiment and analysis as in (top), but using secondary antibodies only. Positions of molecular markers are indicated on the right as 100 or $150 \mathrm{kDa}$. Total amount of 293 cell lysate loaded is in $\mu \mathrm{g}$.

L1 ORF2 protein of mouse and human origin have been previously reported [27-29].

We have developed a custom monoclonal antibody to the human L1 ORF2p endonuclease domain that will help to advance future studies involving ORF2p expression and function. The monoclonal nature of the antibody provides a continuous source of antibody, thereby eliminating the inherent issue with reproducibility commonly associated with different batches of polyclonal antibodies raised against the same antigen. Similar to previously reported polyclonal antibodies [27], our monoclonal anti-ORF2p antibody detects untagged ORF2 protein expressed from the plasmids containing fulllength wild-type or codon-optimized L1 elements. This characteristic is beneficial because the addition of different tags can interfere with L1 protein function or subcellular localization [20,51]. Using bacterially purified endonuclease protein, we generated a standard curve that allowed us to determine the sensitivity of our monoclonal antibodies, which is about $10 \mathrm{ng}$ of the purified protein under the described detection conditions (Figure 6). Consistent with the previous reports, we confirmed that codon-optimization of the human L1 ORF2 sequence results in a 5- to 6-fold increase in EN protein production $[35,36]$. As we were unable to detect endogenously expressed L1 ORF2p in HeLa and 293 cells, our calculations suggest that endogenous levels of L1 ORF2p expression are less than $10 \mathrm{ng}$ of protein per $10 \mu \mathrm{g}$ of cellular lysate.

Additionally, we determined that our antibody specifically recognizes human, but not mouse, ORF2 protein despite the relatively strong sequence conservation between the endonuclease domains of the two proteins (Additional file 5: Figure S5) [36,52]. This feature is useful for studies involving mouse cells and human ORF2 protein. We also ascertained that the epitope recognized by the monoclonal anti-ORF2p antibody includes amino acid 205 of the human ORF2p endonuclease domain. This amino acid is required for the ORF2p endonuclease activity and is therefore necessary for L1-driven retrotransposition (Figures 3 and 4). As a result, our antibody exhibits some bias toward detection of the ORF2 proteins containing a functional endonuclease domain at least relative to the status of amino acid 205. Additionally, an alignment of the consensus L1PA1-PA8 ORF2p sequences [52] demonstrated that L1PA3 to 5 have the same sequence as L1PA1, whereas L1PA2, 6, and 7 have one substitution in the core region surrounding amino acid 205 (200-210aa) (Additional file 5: Figure S5). The same analysis identified that L1PA8 varies by two amino acids from the L1PA1 sequence.

This discovery opens up the possibility that our monoclonal antibody may inhibit human L1 endonuclease activity. Suppression of L1 retrotransposition by HIV reverse transcriptase inhibitors has been previously reported $[53,54]$, generating an interest in developing L1-specific inhibitors with the potential to suppress L1-associated damage in vivo. While the use of such RT inhibitors serves as a helpful tool to study the L1 replication cycle, these inhibitors are not specific to L1 as they are also expected to suppress telomerase RT [55]. Furthermore, they have significant side effects in humans [56] and it is not known whether the inhibition of the RT also prevents damage from the L1 endonuclease-induced DNA double-stranded 


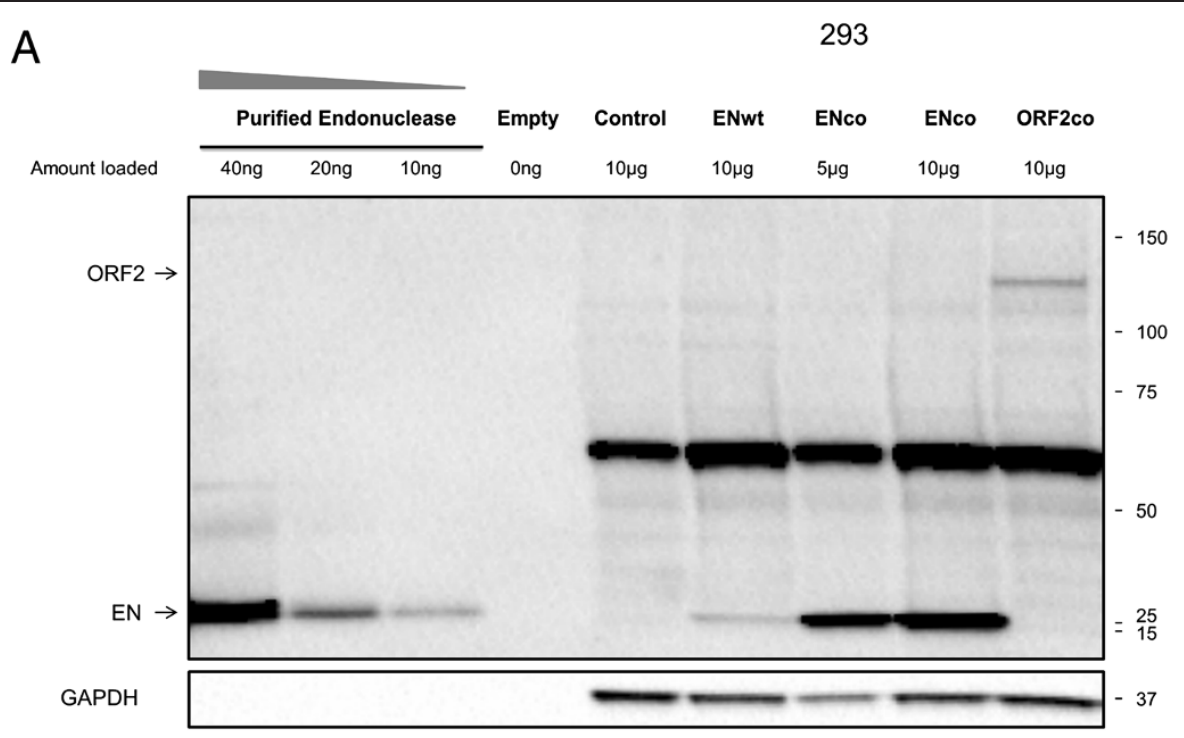

B

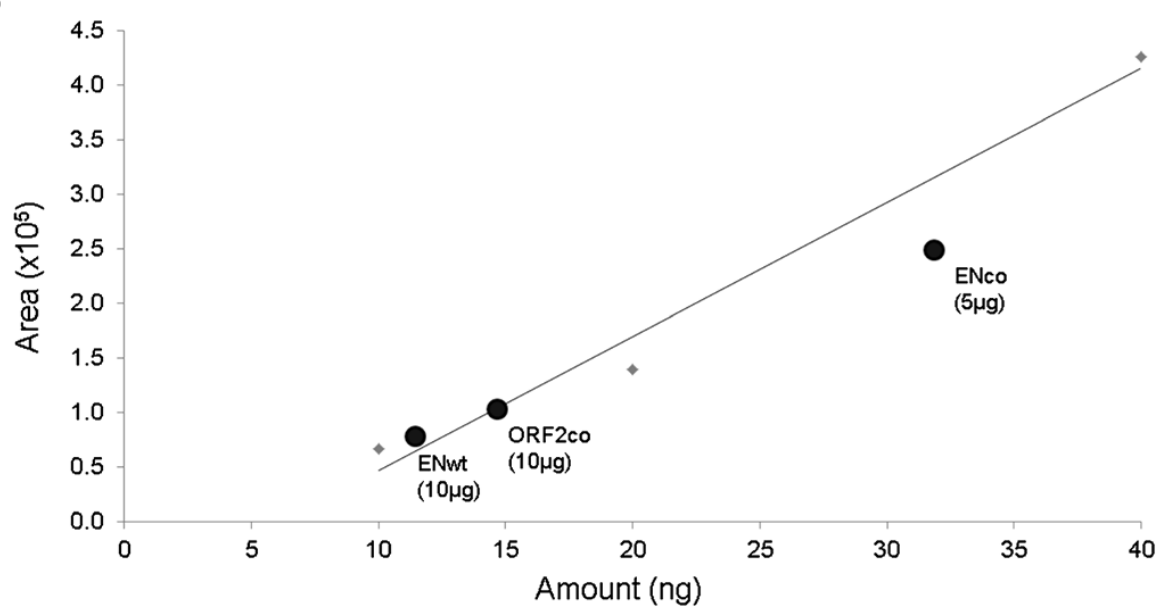

Figure 6 Analysis of sensitivity of the custom anti-human ORF2p monoclonal antibody. (A) Western blot analysis of protein generated from expression plasmids containing wild-type ORF2 endonuclease sequence (ENwt), codon-optimized ORF2 endonuclease sequence (ENco), and codon-optimized ORF2 sequence (ORF2) transiently transfected in 293 cells with our monoclonal antibody; 5 or $10 \mu \mathrm{g}$ of the whole cell lysate was used for analysis as indicated. Control lane indicates cells transiently transfected with an empty vector. Bacterially purified endonuclease was loaded at 0 (empty, buffer only), 10, 20, and $40 \mathrm{ng}$. GAPDH is used as a loading control; 15 to $150 \mathrm{kDa}$ on the right indicate positions of molecular markers. Arrows denote bands of expected sizes for each protein. (B) A standard curve was generated using the quantitation of the increasing amounts of the bacterially purified endonuclease shown in $\mathbf{A}$. Signals detected for ORF2co, ENco, and ENwt are plotted and labeled with the respective names of the proteins.

breaks. Thus, inhibition of L1 endonuclease activity is an attractive approach in order to suppress most, if not all, of the L1-induced damage. The development of either chemical or antibody-based inhibitors are the two of the main approaches generally used for the suppression of enzymatic activities. In addition to the effective inhibition of enzyme activity, efficient delivery, stability, and lack of toxicity are common goals for both types of inhibitors $[57,58]$. The specificity of inhibition is a potential challenge with the development of L1 endonuclease inhibitors because this endonuclease is related to the human APE1, which is involved in the repair of DNA damage by the base excision repair pathway [59]. Using a fluorescencebased in vitro cleavage assay, we demonstrated that our monoclonal anti-ORF2p antibody can reduce L1 endonuclease activity by about $25 \%$ without any inhibitory effect on the in vitro activity of the human APE1 (Additional file 4: Figure S4). While it is not known yet whether the antibody is able to inhibit L1 endonuclease activity in the context of the full-length ORF2 protein or in the cellular environment, these results provide the first proof of principle that an antibody specific to amino acid 205 of the L1 endonuclease can reduce the activity of the enzyme. 

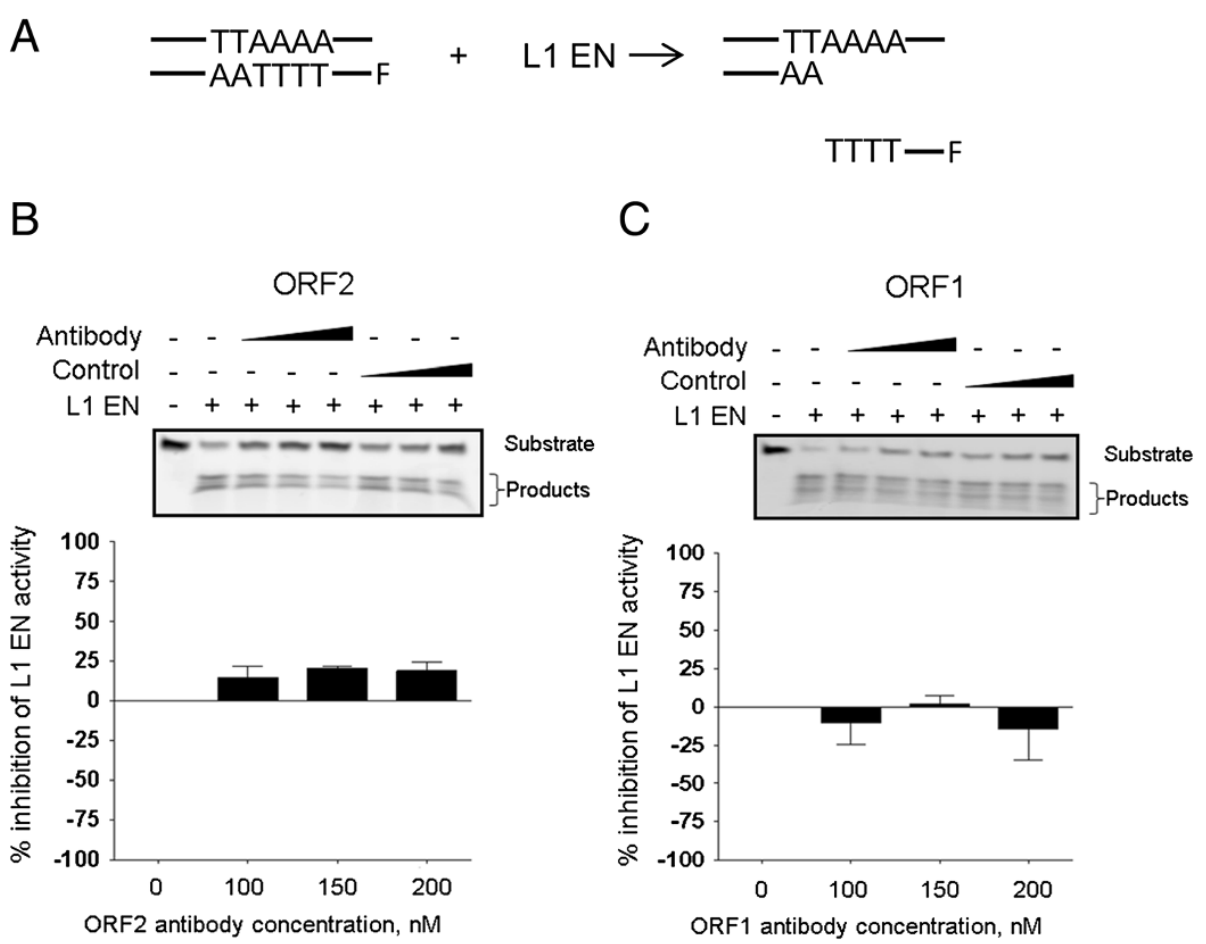

Figure 7 Monoclonal anti-ORF2 $p$ antibody inhibits L1 endonuclease activity in an in vitro endonuclease cleavage assay. (A) Schematic of in vitro endonuclease cleavage assay. Double-stranded DNA containing L1 ORF2 endonuclease consensus target sequence with 5' tagged with fluorophore. L1 ORF2 endonuclease is added, DNA is cleaved releasing the fluorphore, which can be quantitated. (B) (Top) SDS-PAGE analysis of the products resulting from the in vitro endonuclease assay with or without the addition of the monoclonal anti-ORF2 antibody (0, 100, 150, $200 \mathrm{nM}$ ). Antibody (ORF2) denotes the addition of the monoclonal anti-ORF2 antibody, control indicates the addition of the same volume of the buffer used for the reactions containing monoclonal anti-ORF2p antibody, and L1 EN denotes bacterially purified human ORF2 endonuclease. (Bottom) Quantitation of the results of the in vitro endonuclease cleavage assay in A (see Methods). Results were normalized to $0 \mathrm{nM}$ control $(n=3)$. (C) Same experimental approach as in $\mathbf{B}$, but anti-hORF1p antibody was added to the in vitro endonuclease cleavage assay.

\section{Conclusions}

Our data demonstrate that this anti-ORF2p monoclonal antibody will be a useful tool for studies involving human L1 because it is specific to human ORF2p. The antiORF2p monoclonal antibody detects ORF2 protein generated from the ORF2 expression plasmid as well as both codon-optimized and wild-type full-length L1 expression plasmids transiently transfected into human cells. Our data also establish a rationale for the development of antibody-based inhibitors of L1-induced damage.

\section{Methods}

\section{Cells}

FLP-In ${ }^{\mathrm{Tw}}-293$ (Invitrogen) cells were cultured in HyClone Dulbecco's modified Eagle's medium with $10 \%$ fetal bovine serum (Invitrogen) and maintained under $6 \% \mathrm{CO}_{2}$ at $37^{\circ} \mathrm{C}$. HeLa (ATCC CCL2), NIH-3T3 (ATCC CRL-1658), and Ntera2 (ATCC CRL-1973) cells were maintained as previously described [50].

\section{Transfections}

Western blot: 293 cells were seeded at $1.5 \times 10^{6}$ cells per T25 flask and transfected 16 to 18 hours later with $2 \mu \mathrm{g}$ of the human or mouse ORF2 or EN expression plasmids [28], or 1, 2, or $4 \mu \mathrm{g}$ of codon-optimized L1Pa1 [36] (L1co) or wild-type L1.3 (L1wt) [6,36]. Plus reagent $(6 \mu \mathrm{L})$ and Lipofectamine $(8 \mu \mathrm{L})$ (Invitrogen) were used for each ORF2 or EN transfection reaction in serum-free media; $12 \mu \mathrm{L}$ of Plus reagent and $24 \mu \mathrm{L}$ of Lipofectamine were used for each transfection reaction with L1co or L1wt in serum-free media. Transfections with maximum amount of the empty pCDNA plasmid were used as controls. After 3 hours, serum-free media was replaced with serum-containing media, and the cells were harvested at 24 hours after transfection unless otherwise noted in the figure. HeLa and NIH-3T3 cells were seeded at $2 \times 10^{6}$ and $2.5 \times 10^{6}$ cells per T75 flask, respectively, and transfected as previously described using $6 \mu \mathrm{g}$ of plasmid [51], $12 \mu \mathrm{L}$ of Plus reagent, and $18 \mu \mathrm{L}$ or $24 \mu \mathrm{L}$ of Lipofectamine, respectively, in serum-free media.

\section{Total protein extraction}

Total protein was extracted as previously described $[28,51]$ using phosphate buffered saline (PBS; $137 \mathrm{mM}$ $\mathrm{NaCl}$ (Sigma S9888), $2.7 \mathrm{mM} \mathrm{KCl}$ (Sigma P4505), $10 \mathrm{mM}$ $\mathrm{Na}_{2} \mathrm{HPO}_{4}$ (Sigma S3264), 2 mM KH $\mathrm{PO}_{4}$ (Sigma P9791), 
$\mathrm{pH}=7.4$ ), $5 \mathrm{mM}$ ethylenediaminetetraacetic acid (Sigma ED), and $0.02 \%$ sodium azide (Sigma S2002). Lysis buffer was supplemented with phosphatase inhibitors 2 and 3 (Sigma P5726 and P0044, respectively) and Halt Protease inhibitors at $10 \mu \mathrm{L} / \mathrm{mL}$ each. The samples were subjected to two freeze $\left(-80^{\circ} \mathrm{C}\right) /$ thaw $\left(25^{\circ} \mathrm{C}\right)$ cycles. The samples were sonicated three times for 10 seconds at 12 watts RMS using a $3 \mathrm{~mm}$ wide QSonica Microson homogenizer with Microson ultra sonic disruptor XL2000 (Misonix). The protein concentration of each sample was determined using $595 \mathrm{~nm}$ wavelength OD values against a bovine serum albumin standard.

\section{Western blot analysis}

A 10 to $20 \mu \mathrm{g}$ of total protein were combined with $2 \times$ Laemmli buffer and 1.6 $\mu \mathrm{L}(14.3 \mathrm{M}) \beta$-mercaptoethanol and boiled for 5 minutes prior to fractionation on Tris Acetate $3-8 \%$ Midi gels, Bis Tris 4 to $12 \%$ Midi gels (Invitrogen), and transferred onto nitrocellulose membranes (iBlot System; Invitrogen). Membranes containing fractionated protein samples were blocked for 1 hour in PBS-Tween containing 5\% milk and incubated with a 1:250 dilution of custom polyclonal antibodies against the mouse ORF2p endonuclease [28], a 1:500 dilution of custom polyclonal antibodies against the human ORF2p endonuclease $[27,28]$ antibodies, or a 1:250 dilution of custom monoclonal antibodies against the human ORF2p endonuclease overnight at $4^{\circ} \mathrm{C}$. Detection was carried out using horseradish peroxidase (HRP)-conjugated secondary antibodies, either HRP-donkey anti-goat (Santa Cruz; sc-2020), HRP-donkey anti-rabbit (Santa Cruz; sc-2317), or HRP-goat anti-mouse (Santa Cruz; sc-2031) at a 1:5,000 dilution in 3\% milk in PBS-Tween for 1 hour. A 1:5000 dilution of GAPDH antibodies (Santa Cruz sc-25778) was used as an equal loading control. A HRP conjugated monoclonal antibody against the $6 \times$ HIS tag (Pierce MA1-21315-HRP) was used at a 1:2000 dilution. All Western blots were developed using Clarity $^{\mathrm{TM}}$ Western ECL Substrate (Bio-Rad, Cat. \#170-5061).

For SDS Tris Glycine gels (Figure 5; Additional file 4: Figure S4), 3 to $20 \mu \mathrm{g}$ of total protein were combined with $2 \times$ Tris Glycine SDS sample buffer and 1.6 $\mu \mathrm{L}(14.3 \mathrm{M})$ $\beta$-mercaptoethanol and boiled for 5 minutes prior to fractionation on Tris Glycine 4\% Mini gels with Tris Glycine SDS running buffer (Invitrogen) and transfer onto nitrocellulose membranes. Membranes containing fractionated proteins were blocked for 1 hour in PBSTween containing 5\% milk at room temperature. The membranes were then incubated overnight at $4^{\circ} \mathrm{C}$ with $1 \mathrm{~mL}$ of Ab-containing hybridoma supernatant in a blocking mixture containing $4 \mathrm{~mL}$ of media collected from NIH-3T3 cells cultured for 24 hours and $15 \mathrm{~mL}$ of $3 \%$ milk in PBS-Tween. Detection was carried out using HRP-conjugated secondary antibodies HRP-goat anti-mouse (Santa Cruz; sc-2031) at a 1:5,000 dilution in $3 \%$ milk in PBS-Tween for 1 hour. All Western blots were developed using Clarity ${ }^{\text {Tx }}$ Western ECL Substrate (Bio-Rad, Cat. \#170-5061).

For Tris Glycine Native gel (Additional file 2: Figure S2), $100 \mathrm{ng}$ of bacterially purified human ORF2p endonuclease was combined with $2 \times$ Native Tris Glycine sample buffer along with 5\% GelCode Blue Stain Reagent (Thermo Scientific, Prod \# 24592) and fractionated on a Tris Glycine 4 to $12 \%$ gel with Tris Glycine Native running buffer (Invitrogen). Fractionated proteins were transferred onto a nitrocellulose membrane. Membranes containing fractionated proteins were blocked for 1 hour in PBSTween containing 5\% milk at room temperature. The membranes were then incubated overnight at $4^{\circ} \mathrm{C}$ with $1 \mathrm{~mL}$ of Ab-containing hybridoma supernatant in a blocking mixture containing $4 \mathrm{~mL}$ of media collected from NIH-3T3 cells cultured for 24 hours and $15 \mathrm{~mL}$ of $3 \%$ milk in PBS-Tween. Detection was carried out using HRP-conjugated secondary antibodies HRP-goat anti-mouse (Santa Cruz; sc-2031) at a 1:5,000 dilution in 3\% milk in PBS-Tween for 1 hour. All Western blots were developed using Clarity ${ }^{\text {тм }}$ Western ECL Substrate (Bio-Rad, Cat. \#170-5061).

\section{Plasmids}

All endonuclease constructs used in this study have been previously described [28], as well as ORF2 constructs [28] and L1PA1 (codon-optimized full-length L1) [36]. 'L1wt' is JM101/L1.3 no tag [6].

\section{ORF2p endonuclease purification}

A human ORF2 endonuclease was expressed in bacteria and the EN protein was purified as previously described [31-33].

\section{Monoclonal antibody production}

hORF2p endonuclease was bacterially purified as previously described [31,32]. This purified human ORF2 endonuclease protein was used for immunization of 6 $\mathrm{Balb} / \mathrm{c}$ mice to generate monoclonal anti-ORF2p antibodies following a standard immunization protocol. Briefly, three sequential immunizations (with 2 week intervals between the injections) with antigen, (purified ORF2p endonuclease diluted in saline) in complete Freund's Adjuvant for the first injection and incomplete Freund's Adjuvant for the second and third injection, injected intraperitoneally, were performed. The fourth and final immunization was done using the antigen in saline. Mice were bled and tested using ELISA to determine which mouse to use as the source of B-cells for hybridoma production. Electrofusion was performed between B-cells harvested from the spleen and myeloma cells to produce hybridomas. Resulting hybridoma 
clones were screened with indirect ELISA to identify positive clones. The final stock of antibody was obtained by protein-G affinity column purification. The antibodies were stored in a PBS with $0.02 \% \mathrm{~W} / \mathrm{V}$ sodium azide storage solution. The affinity purified hORF2p monoclonal antibodies were used for subsequent testing.

\section{The LINE-1 EN cleavage assay}

The LINE-1 EN was expressed and purified as described previously [31,32]. The LINE1 EN cleavage assay was performed using $200 \mathrm{nM}$ purified LINE1 EN, $100 \mathrm{nM}$ of a duplexed oligonucleotide containing LINE-1 EN target site. The reaction buffer contained $20 \mathrm{mM}$ Hepes (pH 6.5), $150 \mathrm{mM} \mathrm{NaCl}, 1 \mathrm{mM} \mathrm{MgCl}_{2}, 1 \mathrm{mM}$ dithiothreotol (DTT), 1\% dimethyl sulfoxide (DMSO), $0.1 \%$ triton, and $0.01 \%$ sodium azide.

The effect of the monoclonal anti-ORF2p antibody on LINE1 EN activity was tested using three concentrations: $100 \mathrm{nM}, 150 \mathrm{nM}$, and $200 \mathrm{nM}$. The antibody was diluted into the above described reaction buffer just prior to use. The same was done for the anti-hORF1p antibody [51]. A buffer control was used for background subtraction, in which the same volume of buffer alone as the volume of buffer containing antibody was added to the reactions. The LINE-1 EN and APE1 EN cleavage reactions were carried out at $37^{\circ} \mathrm{C}$ for 30 minutes. The reactions were stopped by quenching on ice and the addition of stop solution: $1 \times$ Tris borate EDTA buffer, $80 \%$ formamide, $0.01 \mathrm{mM}$ EDTA, and xylene cyanol. The samples were run on $18 \%$ denaturing acrylamide gels and were analyzed using the Typhoon imager (GE Lifesciences). Fluorescense intensity (FI) was measured using Image Quant software (GE Lifesciences) and graphed using Prism software (GraphPad software, LLC). The percent inhibition of each reaction was determined using the following equation: \% Inh $=100 \times\left(1-\left(\mathrm{FI}_{\text {Antibody }}-\mathrm{FI}_{\text {BufferControl }}\right) /\right.$ $\left(\mathrm{FI}_{\text {L1/APE1 EN }}-\mathrm{FI}_{\text {Buffer Control }}\right)$.

\section{The APE1 EN cleavage assay}

The purified APE1 EN was purchased from New England Biolabs. The assay was performed using 0.01 and 0.1 units of enzyme and $200 \mathrm{nM}$ of duplexed oligonucleotide containing an abasic site. The sequence of the oligonucleotide was based upon previously published work [59]. The reaction buffer contained $50 \mathrm{mM}$ potassium acetate $20 \mathrm{mM}$ tris-acetate, $10 \mathrm{mM}$ magnesium acetate, $1 \mathrm{mM}$ DTT, $1 \%$ DMSO, $0.1 \%$ triton, and $0.01 \%$ sodium azide.

\section{Annealing oligonucleotides}

All oligonucleotides were purchased from Integrated DNA Technologies. The oligonucleotides used in the assays were annealed by adding equivalent amounts of each complimentary nucleotide in annealing buffer $(50 \mathrm{mM}$ Hepes ( $\mathrm{pH} 7.5)$ and $100 \mathrm{mM} \mathrm{NaCl}$. The samples were incubated in boiling water for 5 minutes and slow cooled for 1 hour in the dark. The sequence for the LINE1 EN oligonucleotides used in the assay are as follows: 5'/AlexaFluor488/CCTTTTTTTTTAACCGC3' and 5'GCGGTTAAAAAAAAAGG3'. The sequence for the APE1 EN oligonucleotides used in the assay are as follows: 5'/AlexaFluor488/GCCCCC_GGGGACGTACGATA TCCCGCTCC3" (where "-" represents an abasic site) and 5'GGAGCGGGATATCGTACGTCCCCCGGGGGC3'.

\section{Alignment of human and mouse ORF2 $p$ endonuclease domains}

Human L1PA family consensus sequences [52] and L1 Spa [60] ORF2 sequence were converted to amino acid sequences and aligned using DNASTAR MegAlign program through the Clustal $\mathrm{V}$ method utilizing a gap penalty of ' 10 ' and a gap penalty length of ' 10 '.

\section{Calculation of the number of protein molecules}

The molecular weight of all proteins was calculated based on their amino acid composition using EditSeq software. The number of molecules detected by monoclonal anti-ORF2p antibody was calculated using the following formula:

$$
\begin{aligned}
\mathrm{X} \text { molecules }= & {[\text { Mass }(\mathrm{g}) / \text { Molecular weight of a }} \\
& \text { specific protein }(\mathrm{g} / \mathrm{mol})] \\
& \times 6.022 \times 10^{23}\left(\mathrm{~mol}^{-1}\right)
\end{aligned}
$$

\section{Additional files}

Additional file 1: Figure S1. Analysis of expression of functional and non-functional human ORF2 endonuclease domains in NIH-3T3 cells. Western blot analysis of proteins generated from expression plasmids containing codon-optimized functional (EN) and non-functional

(EN 205,230) ORF2 endonuclease sequences transiently transfected in NIH-3T3 cells with anti-human ORF2p monoclonal antibody (top), anti-human ORF2p polyclonal antibodies (middle), or GAPDH (bottom) Control lane indicates cells transiently transfected with an empty vector; 25 and $37 \mathrm{kDa}$ are molecular markers.

Additional file 2: Figure S2. Analysis of endogenous ORF2p in different cell lines. (Top) Western blot analysis of total cell lysate from the following cell lines: NIH-3T3, 293, Ntera2, and HeLa using hybridoma supernatant. Protein lysate from 293 cells transiently transfected with an expression plasmid containing codon-optimized ORF2 was used as a positive control for ORF2p expression (third lane). Control lane indicates 293 cells transiently transfected with an empty vector. Positions of molecular markers are indicated on the right as 100 or $150 \mathrm{kDa}$. (Bottom) The same experiment and analysis as in (top), but using secondary antibodies only. Positions of molecular markers are indicated on the right as 100 or $150 \mathrm{kDa}$. Total amount of cell lysate loaded is in micrograms $(\mu \mathrm{g})$.

Additional file 3: Figure S3. Analysis of functional ORF2p endonuclease in native conformation. Western blot analysis of the bacterially purified ORF2p endonuclease (EN) fractionated under native conditions using hybridoma supernatant. Buffer lane indicates storage buffer used for purified ORF2p endonuclease.

Additional file 4: Figure S4. Monoclonal anti-ORF2p antibody does not inhibit the APE1 endonuclease activity in vitro. (Top) SDS-PAGE analysis of in vitro APE1 endonuclease cleavage assay using monoclonal anti-ORF2 
antibody. ORF2 antibody denotes the addition of $200 \mathrm{nM}$ of the monoclonal anti-ORF2p antibody, control indicates the addition of the same volume of the buffer used for the reactions containing monoclonal anti-ORF2 antibody, and APE1 denotes bacterially purified human APE1 endonuclease; 0.1 and 0.01 units of APE1 were tested. (Bottom) Quantitation of the results of the in vitro APE1 endonuclease cleavage assay in A. Results were normalized to $0 \mathrm{nM}$ control $(n=3)$. Equation used to determine percent (\%) inhibition is listed in the methods section.

Additional file 5: Figure S5. Analysis of ORF2p endonuclease conservation in human and mouse. Alignment of ORF2p endonucleases of L1Pa families in humans and the ORF2p endonuclease domain of mouse L1 Spa. Black arrow indicates area of the epitope of anti-ORF2p monoclonal antibody.

\section{Abbreviations}

APE: Apurinic/apyrimidinic endonuclease 1; EN: N-terminal endonuclease: HRP: Horseradish peroxidase; KDa: Kilodalton; L1: Long interspersed element-1; ORFs: Open reading frames; PBS: Phosphate buffered saline; RNP: Ribonucleoprotein; RT: Reverse transcriptase; SINE: Short interspersed element; SVA: SINE-VNTR-Alu elements.

\section{Competing interests}

The authors declare that they have no competing interests.

\section{Authors' contributions}

VPB conceived the idea, MS, CBD, GS, KJK, DLD, and VPB designed and performed experiments, analyzed collected data, and wrote the manuscript. All authors read and approved the final manuscript.

\section{Acknowledgements}

MS was supported by the Louisiana State Board of Regents Graduate Research Fellowship. CBD was supported by an Institutional Development Award (IDeA) from the NIGMS/NIH P20GM10342, start-up funds from the Louisiana Cancer Research Consortium, and in part by NIMHD/NIH/DHHS 2G12MD007595-06. VPB was supported by the Ellison Medical Foundation New Scholar in Aging Research (AG-NS-0447-08), NIGMS/NIH P20GM10342, and Life Extension Foundation.

\section{Author details}

'Department of Structural and Cellular Biology, Tulane School of Medicine, Tulane Cancer Center, and Tulane Center for Aging, New Orleans, LA 70112, USA. ${ }^{2}$ Department of Biology, Xavier University, 1 Drexel Drive, Box 85, New Orleans, LA 70125-7918, USA. ${ }^{3}$ Department of Epidemiology, Tulane School of Public Health, Tulane Cancer Center, New Orleans, LA 70112, USA.

Received: 29 August 2014 Accepted: 14 November 2014 Published: 10 December 2014

\section{References}

1. Moran JV, Holmes SE, Naas TP, DeBerardinis RJ, Boeke JD, Kazazian HH Jr: High frequency retrotransposition in cultured mammalian cells. Cell 1996, 87(5):917-927.

2. Dewannieux M, Esnault C, Heidmann T: LINE-mediated retrotransposition of marked Alu sequences. Nat Genet 2003, 35(1):41-48.

3. Ostertag EM, Goodier JL, Zhang Y, Kazazian HH Jr: SVA Elements are nonautonomous retrotransposons that cause disease in humans. Am J Hum Genet 2003, 73(6):1444-1451.

4. Esnault C, Maestre J, Heidmann T: Human LINE retrotransposons generate processed pseudogenes. Nat Genet 2000, 24(4):363-367.

5. Kulpa DA, Moran JV: Ribonucleoprotein particle formation is necessary but not sufficient for LINE-1 retrotransposition. Hum Mol Genet 2005, 14(21):3237-3248.

6. Wei W, Gilbert N, Ooi SL, Lawler JF, Ostertag EM, Kazazian HH, Boeke JD, Moran JV: Human L1 retrotransposition: cispreference versus trans complementation. Mol Cell Biol 2001, 21(4):1429-1439.

7. Kolosha VO, Martin SL: In vitro properties of the first ORF protein from mouse LINE-1 support its role in ribonucleoprotein particle formation during retrotransposition. Proc Natl Acad Sci U S A 1997, 94(19):10155-10160.
8. Wallace N, Wagstaff BJ, Deininger PL, Roy-Engel AM: LINE-1 ORF1 protein enhances Alu SINE retrotransposition. Gene 2008, 419(1-2):1-6.

9. Luan DD, Korman MH, Jakubczak JL, Eickbush TH: Reverse transcription of R2Bm RNA is primed by a nick at the chromosomal target site: A mechanism for non-LTR retrotransposition. Cell 1993, 72(4):595-605.

10. Cost GJFQJABJD: Human L1 element target-primed reverse transcription in vitro. EMBO J 2002, 21(21):5899-5910.

11. Lander ES, Linton LM, Birren B, Nusbaum C, Zody MC, Baldwin J, Devon K, Dewar K, Doyle M, FitzHugh W, Funke R, Gage D, Harris K, Heaford A, Howland J, Kann L, Lehoczky J, LeVine R, McEwan P, McKernan K, Meldrim J, Mesirov JP, Miranda C, Morris W, Naylor J, Raymond C, Rosetti M, Santos R, Sheridan A, Sougnez C, et al: Initial sequencing and analysis of the human genome. Nature 2001, 409(6822):860-921.

12. Konkel MK, Wang J, Liang P, Batzer MA: Identification and characterization of novel polymorphic LINE-1 insertions through comparison of two human genome sequence assemblies. Gene 2007, 390(1-2):28-38.

13. Beck CR, Collier P, Macfarlane C, Malig M, Kidd JM, Eichler EE, Badge RM, Moran JV: LINE-1 retrotransposition activity in human genomes. Cell 2010, 141(7):1159-1170.

14. Huang CRL, Schneider AM, Lu Y, Niranjan T, Shen P, Robinson MA, Steranka JP, Valle D, Civin Cl, Wang T, Wheelan SJ, Ji H, Boeke JD, Burns KH: Mobile Interspersed repeats are major structural variants in the human genome. Cell 2010, 141(7):1171-1182.

15. Ewing $A D$, Kazazian $H H$ : Whole-genome resequencing allows detection of many rare LINE-1 insertion alleles in humans. Genome Res 2011, 21(6):985-990

16. Brouha B, Schustak J, Badge RM, Lutz-Prigge S, Farley AH, Moran JV, Kazazian HH: Hot L1s account for the bulk of retrotransposition in the human population. Proc Natl Acad Sci U S A 2003, 100(9):5280-5285.

17. Basame S, Wai-lun Li P, Howard G, Branciforte D, Keller D, Martin SL: Spatial assembly and RNA binding stoichiometry of a LINE-1 protein essential for retrotransposition. J Mol Biol 2006, 357(2):351-357.

18. Khazina E, Truffault V, Büttner R, Schmidt S, Coles M, Weichenrieder O: Trimeric structure and flexibility of the L1ORF1 protein in human L1 retrotransposition. Nat Struct Mol Biol 2011, 18(9):1006-1014.

19. Callahan KE, Hickman AB, Jones CE, Ghirlando R, Furano AV: Polymerization and nucleic acid-binding properties of human L1 ORF1 protein. Nucleic Acids Res 2012, 40(2):813-827.

20. Taylor MS, LaCava J, Mita P, Molloy KR, Huang CRL, Li D, Adney EM, Jiang H, Burns KH, Chait BT, Rout MP, Boeke JD, Dai L: Affinity proteomics reveals human host factors implicated in discrete stages of LINE-1 retrotransposition. Cell 2013, 155(5):1034-1048.

21. Feng Q, Moran JV, Kazazian HH Jr, Boeke JD: Human L1 retrotransposon encodes a conserved endonuclease required for retrotransposition. Cell 1996, 87(5):905-916.

22. Xiong Y, Eickbush TH: Origin and evolution of retroelements based upon their reverse transcriptase sequences. EMBO J 1990, 9(10):3353.

23. Fanning TG, Singer MF: LINE-1: a mammalian transposable element. Biochim Biophys Acta 1987, 910(3):203-212

24. Piskareva O, Ernst C, Higgins N, Schmatchenko V: The carboxy-terminal segment of the human LINE-1 ORF2 protein is involved in RNA binding. FEBS Open Bio 2013, 3:433-437.

25. Alisch RS, Garcia-Perez JL, Muotri AR, Gage FH, Moran JV: Unconventional translation of mammalian LINE-1 retrotransposons. Gene Dev 2006, 20(2):210-224.

26. Li PW-L, Li J, Timmerman SL, Krushel LA, Martin SL: The dicistronic RNA from the mouse LINE-1 retrotransposon contains an internal ribosome entry site upstream of each ORF: implications for retrotransposition. Nucleic Acids Res 2006, 34(3):853-864.

27. Ergün S, Buschmann C, Heukeshoven J, Dammann K, Schnieders F, Lauke H, Chalajour F, Kilic N, Strätling WH, Schumann GG: Cell type-specific expression of LINE-1 open reading frames 1 and 2 in fetal and adult human tissues. J Biol Chem 2004, 279(26):27753-27763.

28. Kines KJ, Sokolowski M, De Haro DL, Christian CM, Belancio VP: Potential for genomic instability associated with retrotranspositionally-incompetent L1 loci. Nucleic Acids Res 2014, 42(16):10488-10502.

29. Goodier JL, Ostertag EM, Engleka KA, Seleme MC, Kazazian HH: A potentia role for the nucleolus in L1 retrotransposition. Hum Mol Genet 2004, 13(10):1041-1048.

30. Doucet AJ, Hulme AE, Sahinovic E, Kulpa DA, Moldovan JB, Kopera HC, Athanikar JN, Hasnaoui M, Bucheton A, Moran JV, Gilbert N: 
Characterization of LINE-1 ribonucleoprotein particles. PLOS Genet 2010, 6(10):e1001150.

31. Repanas K, Zingler N, Layer LE, Schumann GG, Perrakis A, Weichenrieder O: Determinants for DNA target structure selectivity of the human LINE-1 retrotransposon endonuclease. Nucleic Acids Res 2007, 35(14):4914-4926.

32. Nesterova IV, Bennett CA, Erdem SS, Hammer RP, Deininger PL, Soper SA: Near-IR single fluorophore quenching system based on phthalocyanine (Pc) aggregation and its application for monitoring inhibitor/activator action on a therapeutic target: L1-EN. Analyst 2011, 136(6):1103-1105.

33. Weichenrieder $\mathrm{O}$, Repanas K, Perrakis A: Crystal structure of the targeting endonuclease of the human LINE-1 retrotransposon. Structure 2004, 12(6):975-986.

34. Morrish TA, Gilbert N, Myers JS, Vincent BJ, Stamato TD, Taccioli GE, Batzer MA, Moran JV: DNA repair mediated by endonuclease-independent LINE-1 retrotransposition. Nat Genet 2002, 31(2):159-165.

35. Han JS, Boeke JD: A highly active synthetic mammalian retrotransposon. Nature 2004, 429(6989):314-318.

36. Wagstaff BJ, Barnerßoi M, Roy-Engel AM: Evolutionary conservation of the functional modularity of primate and murine LINE-1 elements. PLOS One 2011, 6(5):e19672.

37. Gasior SL, Wakeman TP, Xu B, Deininger PL: The human LINE-1 retrotransposon creates DNA double-strand breaks. J Mol Biol 2006, 357(5):1383-1393.

38. Robberecht C, Voet T, Esteki MZ, Nowakowska BA, Vermeesch JR: Nonallelic homologous recombination between retrotransposable elements is a driver of de novo unbalanced translocations. Genome Res 2013, 23(3):411-418.

39. Dombroski BA, Mathias SL, Nanthakumar E, Scott AF, Kazazian HH: Isolation of an active human transposable element. Science 1991, 254:1805-1808.

40. Han K, Lee J, Meyer TJ, Remedios P, Goodwin L, Batzer MA: L1 recombination-associated deletions generate human genomic variation. Proc Natl Acad Sci U S A 2008, 105(49):19366-19371.

41. Miki Y, Nishisho I, Horii A, Miyoshi Y, Utsunomiya J, Kinzler KW, Vogelstein B, Nakamura Y: Disruption of the APC gene by a retrotransposal insertion of L1 sequence in a colon cancer. Cancer Res 1992, 52(3):643-645.

42. Pickeral OK, Makałowski W, Boguski MS, Boeke JD: Frequent human genomic DNA transduction driven by LINE-1 retrotransposition. Genome Res 2000, 10(4):411-415.

43. Zhang A, Dong B, Doucet AJ, Moldovan JB, Moran JV, Silverman RH: RNase $L$ restricts the mobility of engineered retrotransposons in cultured human cells. Nucleic Acids Res 2014, 42(6):3803-3820.

44. Yang N, Kazazian HH: L1 retrotransposition is suppressed by endogenously encoded small interfering RNAs in human cultured cells. Nat Struct Mol Biol 2006, 13(9):763-771.

45. Goodier JL, Cheung LE, Kazazian HH: Mapping the LINE1 ORF1 protein interactome reveals associated inhibitors of human retrotransposition. Nucleic Acids Res 2013, 41(15):7401-7419.

46. Horn AV, Klawitter S, Held U, Berger A, Jaguva Vasudevan AA, Bock A, Hofmann H, Hanschmann K-MO, Trösemeier J-H, Flory E, Jabulowsky RA, Han JS, Löwer J, Löwer R, Münk C, Schumann GG: Human LINE-1 restriction by $A P O B E C 3 C$ is deaminase independent and mediated by an ORF1p interaction that affects LINE reverse transcriptase activity. Nucleic Acids Res 2014, 42(1):396-416.

47. Belancio VP, Hedges DJ, Deininger P: LINE-1 RNA splicing and influences on mammalian gene expression. Nucleic Acids Res 2006, 34(5):1512-1521.

48. Bogerd HP, Wiegand HL, Hulme AE, Garcia-Perez JL, O'Shea KS, Moran JV, Cullen BR: Cellular inhibitors of long interspersed element 1 and Alu retrotransposition. Proc Natl Acad Sci U S A 2006, 103(23):8780-8785.

49. de Haro D, Kines KJ, Sokolowski M, Dauchy RT, Streva VA, Hill SM, Hanifin JP, Brainard GC, Blask DE, Belancio VP: Regulation of L1 expression and retrotransposition by melatonin and its receptor: implications for cancer risk associated with light exposure at night. Nucleic Acids Res 2014, 42(12):7694-7707.

50. Perepelitsa-Belancio $V$, Deininger P: RNA truncation by premature polyadenylation attenuates human mobile element activity. Nat Genet 2003, 35(4):363-366.

51. Sokolowski M, de Haro D, Christian CM, Kines KJ, Belancio VP: Characterization of L1 ORF1p self-interaction and cellular localization using a mammalian two-hybrid system. PLoS One 2013, 8(12):e82021.
52. Khan H, Smit A, Boissinot S: Molecular evolution and tempo of amplification of human LINE-1 retrotransposons since the origin of primates. Genome Res 2006, 16(1):78-87.

53. Dai L, Huang Q, Boeke J: Effect of reverse transcriptase inhibitors on LINE-1 and Ty1 reverse transcriptase activities and on LINE-1 retrotransposition. BMC Biochem 2011, 12(1):18.

54. Kroutter EN, Belancio VP, Wagstaff BJ, Roy-Engel AM: The RNA polymerase dictates ORF1 requirement and timing of LINE and SINE retrotransposition. PLoS Genet 2009, 5(4):e1000458.

55. Strahl C, Blackburn EH: Effects of reverse transcriptase inhibitors on telomere length and telomerase activity in two immortalized human cell lines. Mol Cell Biol 1996, 16(1):53-65

56. D'Andrea G, Brisdelli F, Bozzi A: AZT: an old drug with new perspectives. Curr Clin Pharmacol 2008, 3(1):20-37.

57. Imai K, Takaoka A: Comparing antibody and small-molecule therapies for cancer. Nat Rev Cancer 2006, 6(9):714-727.

58. Hidalgo M, Eckhardt SG: Development of matrix metalloproteinase inhibitors in cancer therapy. J Nat/ Cancer Inst 2001, 93(3):178-193.

59. Madhusudan S, Smart F, Shrimpton P, Parsons JL, Gardiner L, Houlbrook S, Talbot DC, Hammonds T, Freemont PA, Sternberg MJ, Dianov GL, Hickson ID: Isolation of a small molecule inhibitor of DNA base excision repair. Nucleic Acids Res 2005, 33(15):4711-4724

60. Naas TP, DeBerardinis RJ, Moran JV, Ostertag EM, Kingsmore SF, Seldin MF, Hayashizaki Y, Martin SL, Kazazian HH: An actively retrotransposing, novel subfamily of mouse L1 elements. EMBO J 1998, 17(2):590-597.

doi:10.1186/s13100-014-0029-x

Cite this article as: Sokolowski et al:: Development of a monoclonal antibody specific to the endonuclease domain of the human LINE-1 ORF2 protein. Mobile DNA 2014 5:29.

\section{Submit your next manuscript to BioMed Central and take full advantage of:}

- Convenient online submission

- Thorough peer review

- No space constraints or color figure charges

- Immediate publication on acceptance

- Inclusion in PubMed, CAS, Scopus and Google Scholar

- Research which is freely available for redistribution 